Artículos Científicos

\title{
Satisfacción laboral y compromiso organizacional del capital humano en el desempeño en instituciones de educación superior
}

\author{
Job Satisfaction and Organizational Commitment of Human Capital in \\ Performance in Higher Education Institutions
}

\section{Satisfação no trabalho e comprometimento organizacional do capital humano no desempenho de instituições de ensino superior}

\author{
Norma Angélica Pedraza Melo \\ Universidad Autónoma de Tamaulipas, México \\ napedraza@docentes.uat.edu.mx \\ https://orcid.org/0000-0001-9566-2880
}

\section{Resumen}

La educación tiene un rol central en la formación de capital humano en las naciones, en particular para México. El objetivo de este estudio fue analizar la relación de prácticas en la gestión del personal, como son las variables de satisfacción laboral, compromiso organizacional, competencia del capital humano, y sus efectos en el desempeño de instituciones de educación superior. El diseño metodológico se abordó con enfoque cuantitativo, alcance explicativo, no experimental y transversal. Se aplicó un cuestionario a directivos de instituciones públicas y privadas, quienes accedieron a responder el instrumento. Se conformó una muestra final de 84 encuestados. Se aplicó el modelo de ecuaciones estructurales, mediante la técnica de mínimos cuadrados parciales, para evaluar las relaciones establecidas en las hipótesis de esta investigación. De acuerdo con los resultados, se determinó que el capital humano y la satisfacción laboral son dos variables que contribuyen positivamente en el desempeño educativo. Ambas fueron consideradas prácticas de valor en la gestión de personal, relacionadas con asegurar que los empleados cuenten con 


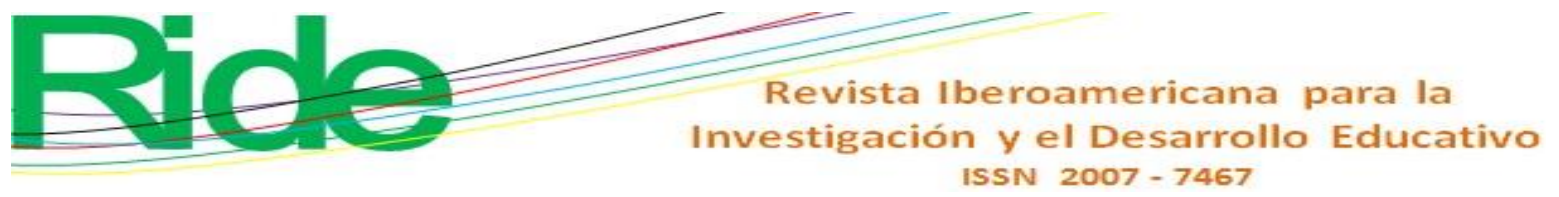

experiencia, habilidades y conocimientos para su función y que den su mejor esfuerzo; vinculadas con el fomento al trabajo en equipo y el aprendizaje continuo; necesarias para que exista libertad de expresión y reconocimiento por el trabajo bien hecho, así como la posibilidad de crecer en la organización, y, entre otras, para que las sugerencias que presentan sean tomadas en cuenta, puesto que ello contribuye a mejorar la imagen institucional, la calidad de los procesos y servicios educativos, la formación de calidad de los alumnos, así como el logro de objetivos e indicadores académicos. Por lo que, en conclusión, estos hallazgos son importantes para que la gerencia educativa contemple, en el diseño de sus prácticas de gestión de recursos humanos, estrategias que favorezcan potenciar las competencias de sus empleados y su satisfacción laboral. Ello en beneficio de mejorar su desempeño educativo.

Palabras clave: calidad académica, desempeño educativo, docencia, enseñanza superior, universidad.

\section{Abstract}

Education has a central role in the formation of human capital in nations, particularly for Mexico. The objective of this study was to analyze the relationship of practices in personnel management, such as the variables of job satisfaction, organizational commitment, competence of human capital and its effects on performance in higher education universities. The methodological design was approached with a quantitative approach, explanatory, non-experimental and transverse scope. Questionnaire was applied to senior management of public and private institutions, who agreed to respond to the instrument. A final sample of 84 respondents was formed. The model of structural equations was applied, using the partial least squares technique, to evaluate the relationships established in the hypotheses of this research. According to the results, it was determined that human capital and job satisfaction are two variables that contribute positively towards educational performance; determining that personnel management practices are valued, which are related to ensuring that employees have experience, skills and knowledge for their function, that they give their best effort, teamwork and learning is encouraged, that there is freedom of expression, recognition is given for a job well done, the possibility of applying their abilities and growing in the organization, the suggestions they present are taken into account, since this contributes to improving the institutional image, the quality of educational processes and services, the quality training of students, as well as the achievement of academic objectives and indicators. As far as I 


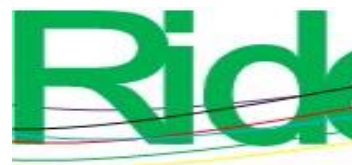

Revista Iberoamericana para la

Investigación y el Desarrollo Educativo

ISSN $2007-7467$

can conclude, these findings are important for educational management to contemplate, in the design of their human resources management practices, strategies that favor enhancing the skills of their employees and their job satisfaction, this in the interest of improving their educational performance.

Keywords: academic quality, educational performance, teaching, higher education, university.

\section{Resumo}

A educação desempenha um papel central na formação de capital humano nas nações, particularmente no México. O objetivo deste estudo foi analisar a relação de práticas em gestão de pessoas, como variáveis de satisfação no trabalho, comprometimento organizacional, competência de capital humano e seus efeitos no desempenho de instituições de ensino superior. O desenho metodológico foi abordado com abordagem quantitativa, explicativa, não experimental e transversal. Um questionário foi aplicado a executivos de instituições públicas e privadas, que concordaram em responder ao instrumento. Uma amostra final de 84 entrevistados foi formada. $\mathrm{O}$ modelo de equações estruturais foi aplicado, utilizando a técnica de mínimos quadrados parciais, para avaliar as relações estabelecidas nas hipóteses desta pesquisa. De acordo com os resultados, determinou-se que capital humano e satisfação no trabalho são duas variáveis que contribuem positivamente para o desempenho educacional. Ambas foram consideradas práticas valiosas na gestão de pessoas, relacionadas à garantia de que os funcionários tenham experiência, habilidades e conhecimentos para sua função e que se esforcem ao máximo; vinculado à promoção do trabalho em equipe e aprendizado contínuo; É necessário que haja liberdade de expressão e reconhecimento por um trabalho bem-feito, bem como a possibilidade de crescer na organização e, entre outros, para que as sugestões apresentadas sejam levadas em consideração, pois isso contribui para melhorar a imagem institucional, a qualidade dos processos e serviços educacionais, a formação de qualidade dos alunos, bem como a consecução dos objetivos e indicadores acadêmicos. Portanto, em conclusão, esses achados são importantes para a gestão educacional contemplar, no desenho de suas práticas de gestão de recursos humanos, estratégias que favoreçam o empoderamento de seus funcionários e a satisfação no trabalho. Isso para o benefício de melhorar seu desempenho educacional.

Palavras-chave: qualidade acadêmica, desempenho educacional, ensino, ensino superior, universidade. 


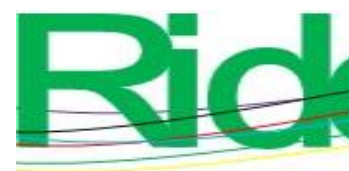

Fecha Recepción: Agosto 2019
Revista Iberoamericana para la

Investigación y el Desarrollo Educativo

ISSN $2007-7467$

Fecha Aceptación: Enero 2020

\section{Introducción}

La educación tiene un papel central en la formación de capital humano competitivo en el contexto actual. Las naciones (particularmente México) enfrentan una serie de desafíos económicos, sociales, ambientales, culturales, tecnológicos y políticos que justifican el hecho de que las gestiones de las instituciones de educación superior (IES) se desarrollen con miras a una visión de futuro, donde sus resultados sean de impacto estratégico en bien del individuo en lo particular, así como de la sociedad en lo general. Al respecto, con fundamento en Pantoja Aguilar (2019), la gestión administrativa y el liderazgo son de suma importancia para el logro del desempeño efectivo en las universidades públicas, pues ambas prácticas aseguran que la gobernanza universitaria contribuya a mejorar el quehacer administrativo y, por consecuencia, los resultados académicos, ello en el marco de limitaciones de recursos financieros y de la exigencia de la calidad académica por las autoridades y la sociedad en general (Ganga, Ramos, Leal y Valdivieso, 2015).

En este sentido, la formación de una sociedad más competitiva se estima producto de la competencia de las personas que son parte de ella. Por ende, la educación superior en este país, como en otras sociedades del mundo, representa un factor clave y decisivo. En palabras de Fernández (2017), se trata de un activo intangible de "carácter estratégico para las naciones, en tanto es el vínculo indisoluble entre la generación de capital humano altamente capacitado y la producción y difusión de conocimientos que favorecen la conformación de sociedades más justas y economías más competitivas” (p. 184).

Por ello, no puede soslayarse en el contexto actual la relevancia de la gestión de los intangibles de una organización, en concreto del capital intelectual, puesto que representan activos inmateriales tales como el conocimiento de los empleados, el aprendizaje organizacional, la cultura y el compromiso organizacional, las relaciones con los stakeholders (clientes, proveedores, sociedad, gobierno, asociaciones), la propiedad intelectual generada (patentes, marcas, diseños industriales, modelos de utilidad, como ejemplos referidos), los sistemas sociotécnicos, los manuales administrativos, las bases de datos y los sistemas de información; todos aquellos recursos y capacidades que normalmente no están claramente manifiestos en los estados financieros de las 


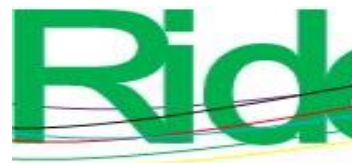

Revista Iberoamericana para la Investigación y el Desarrollo Educativo

ISSN $2007-7467$

entidades económicas, pero que su gestión eficaz puede traer efectos positivos en el desempeño de las organizaciones, así como estrategias para sobrevivir o generar ventajas en su mercado (Bontis, 1998, 2001; Bontis, Chua Chong Keow y Richardson, 2000; Bontis y Serenko, 2009; Gogan, Artene, Sarca y Draghici, 2016; Hashim, Osman y Alhabshi, 2015; Hussinki, Ritala, Vanhala y Kianto, 2017).

De acuerdo con la literatura analizada (Bontis, 1998; Bontis, 2001; Bontis et al., 2000; Bontis y Serenko, 2009), al categorizar el capital intelectual la tipología mayormente aceptada es la que establece tres dimensiones de este constructo: el humano, estructural y relacional. En el marco de esta tipología, Bontis (2001) hace el planteamiento de que el capital humano es el componente central del capital intelectual, puesto que este activo intangible pertenece práctica y mayoritariamente a los trabajadores, de tal suerte que si se retiran se llevan su know how con ellos. De allí la relevancia de que las organizaciones se interesen por establecer las estrategias para captar el conocimiento tácito de los empleados, a fin de documentarlo, socializarlo y gestionarlo estratégicamente para convertirlo en su propiedad.

Por lo anterior, en esta investigación el énfasis se pone en la gestión del personal (dimensión del capital humano), pues representa una de las variables clave para mejorar la calidad del proceso de enseñanza-aprendizaje de los estudiantes, sobre todo porque los bienes que proporcionan las IES son intangibles por naturaleza, como lo es el servicio educativo. Sin duda es apremiante que este tipo de organizaciones, para que sean competitivas, potencien sus activos intangibles provenientes de su capital humano, tengan la capacidad directiva de gestionar esos recursos y habilidades en bien del desempeño educativo (Conde y Martín, 2016; González, López y Sánchez, 2014). Sobre todo, porque en los últimos tiempos la administración de los recursos humanos ha despertado mayor interés e importancia en las organizaciones que ofrecen servicios públicos, a fin de mejorar el desempeño de las tareas que proporcionan a la sociedad (Rodríguez, Retamal, José y Cornejo, 2011).

Así, pues, el objetivo de este estudio es analizar las variables de compromiso organizacional y satisfacción laboral como factores que permiten facilitar la efectividad de la competencia del capital humano hacia el mejor desempeño de las IES, entidades que tienen la gran responsabilidad de contribuir a transformar una sociedad. Por lo que se establecen las siguientes interrogantes: 


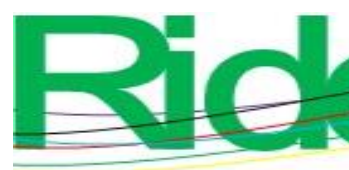

Revista Iberoamericana para la Investigación y el Desarrollo Educativo

ISSN $2007-7467$

PI1: ¿Cuál es la relación entre la satisfacción laboral del capital humano y el desempeño de las IES estudiadas?

PI2: ¿Cuál es la relación del compromiso organizacional del capital humano y el desempeño de las IES estudiadas?

PI3: ¿Cuál es la relación de la competencia del capital humano y el desempeño de las IES estudiadas?

Y para lograr el cometido de este estudio se llevó a cabo una investigación de corte cuantitativo, mediante la recolección de datos por medio de un cuestionario. Dicho instrumento fue aplicado a directivos de las instituciones, gracias a lo cual se conformó una base informativa que, mediante el modelo de ecuaciones estructurales, permitió explorar las relaciones predictivas de las variables independientes y dependiente en las universidades públicas y privadas participantes.

Este informe de investigación se estructura en cuatro grandes apartados. En primer lugar, se describe la literatura analizada desde el contexto de la educación superior en México, y posteriormente se da paso al marco conceptual del desempeño educativo y sus variables explicativas (satisfacción laboral y compromiso organizacional del capital humano). Más adelante, en un segundo apartado, se describe el diseño metodológico que se planificó para llevar a cabo la investigación, en el cual se expone el tipo de estudio, las técnicas de recolección de datos y de análisis de los mismos. En la sección tres, se presentan los principales resultados. Y finalmente, en el cuarto apartado, se da paso a la discusión, conclusiones e implicaciones del estudio.

\section{Contextualización general de la educación superior en México}

Para tener un mayor desarrollo en su productividad y competitividad en México resulta necesario impulsar la cobertura y la calidad de la educación superior. Esto como estrategia para formar capital humano con las cualificaciones que demanda el mercado laboral cambiante, puesto que se estima que en las economías modernas es un factor clave para que los alumnos desarrollen competencias técnicas, profesionales, transversales y disciplinares especializadas que los cualifican para desempeñarse en diversos campos laborales, de acuerdo con la Organización para la Cooperación y el Desarrollo Económicos [OCDE] (2019). Desde la perspectiva de la misma OCDE (2017), se visualiza que este país hace frente a un entorno externo incierto, en donde la economía mundial manifiesta poco crecimiento. Además, padece de rezagos y desigualdades en su desarrollo 


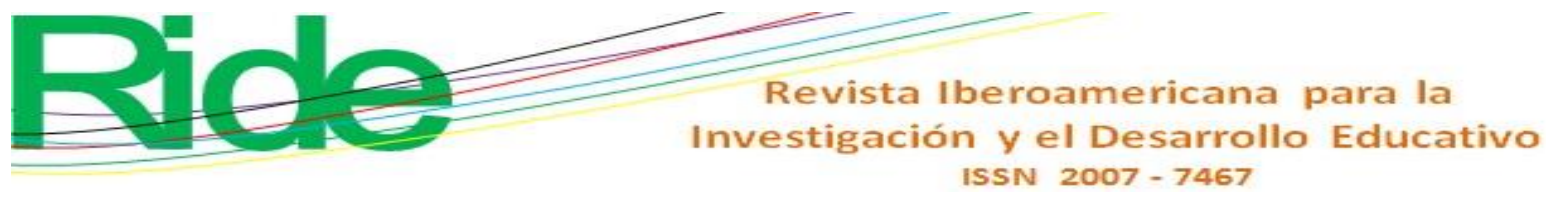

y crecimiento, con motivo de su dependencia del petróleo, los precios bajos del mismo, debido a la baja productividad, a los problemas de corrupción y de la calidad de la educación.

De acuerdo con datos de la Organización de las Naciones Unidas para la Ciencia y la Cultura [Unesco, citado en Fernández, 2017, p.185], a pesar de los grandes avances que México ha logrado en materia de cobertura en educación superior, sigue estando presente la necesidad de mejorar este indicador en relación con otras naciones. Al respecto se señala, por ejemplo, que este país ocupó el último lugar en cobertura entre los miembros de la OCDE que reportaron datos durante el año 2014 (Fernández, 2017).

Asimismo, la OCDE (2019) reporta que la gestión de la educación superior en México tiene que enfrentar el reto de que los egresados de este sistema cuenten con las competencias que demanda la economía y mercado laboral, a efecto de alinear la oferta del talento humano en términos de calidad competitiva. Otro desafío de este sistema refiere a que los subsistemas con los que cuenta este nivel presentan diferencias importantes en materia de gobernanza, financiamiento e influenza del gobierno; lo que produce resultados débiles e insuficientes, principalmente por la ausencia de un marco regulatorio y de políticas públicas que aseguren una cohesión eficaz de los recursos y capacidades de los actores e instituciones que conforman este sistema de educación en el país (Fernández, 2017; OCDE, 2019).

Siguiendo a Fernández (2017), la encomienda para la efectividad del sistema de educación superior en México está puesta en la planeación y gestión estratégica de seis grandes factores de actuación: 1) la cobertura y equidad, 2) la pertinencia, 3) la evaluación de la calidad, 4) la carrera académica, 5) el financiamiento y 6) el tema de la gobernanza. Es precisamente en el factor de la carrera académica donde se tiene interés en el presente estudio, que trata de analizar factores relacionados con la gestión del capital humano en las instituciones de este nivel, puesto que son los profesores quienes tienen la responsabilidad directa de contribuir en la formación de los estudiantes universitarios. En esa misma tónica, Nahid Naderi (2012) enfatiza que las habilidades docentes, los atributos de su personalidad, las herramientas y técnicas en su práctica docente, pueden contribuir al logro de resultados eficaces en las instituciones educativas. Ante este reto, se estima que el capital humano en el contexto de la educación aglutina a las competencias docentes, las habilidades de enseñanza-aprendizaje, el conocimiento y experiencia pedagógica-didáctica, valores y actitudes de compromiso en la formación de sus alumnos (Bontis, 2001; Bontis y Serenko, 2009; Budovich y Nadtochiy, 2019; Linda y Fitria, 2019; Nava y Mercado, 2011; Pedraza, 


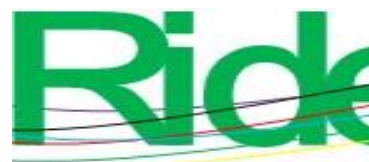

Revista Iberoamericana para la Investigación y el Desarrollo Educativo

ISSN $2007-7467$

Lavín, Marmolejo, Vasconcelo y García, 2017). En nuestros tiempos el capital humano representa el factor y fuente de riqueza para las naciones (Rubio, 2016).

Además, según García, Pérez y Miranda (2018), la modernidad plantea grandes desafíos para las universidades públicas en México; un escenario en el cual la vinculación efectiva puede coadyuvar al logro de los objetivos de este tipo de instituciones, su mejoramiento continuo y su principal misión, que es contribuir a satisfacer las demandas de su entorno, desde su responsabilidad social inherente, y en donde el capital humano tiene un rol importante. Por ejemplo, se menciona a los docentes investigadores que participan en las estrategias y procesos de transferencia tecnológica y de conocimiento, ya que en los tiempos actuales ese tipo de acciones y resultados se esperan de las universidades públicas (investigación aplicada, vinculación efectiva, universidades emprendedoras, responsabilidad social en su actuación, innovación tecnológica, generación y transferencia pertinente del conocimiento). Así, las IES dejan de ser una institución que solo se dedica a formar profesionales para pasar a las exigencias de buscar generar sus propios recursos, según el mercado educativo que atienden (García et al., 2018).

Por ende, se estima que la vinculación con el sector productivo-social es una acción indispensable en la formación pertinente de estudiantes, así como en la contribución efectiva de los docentes e investigadores en las IES, puesto que es el mecanismo que posibilita el trabajo colaborativo y socialmente pertinente para la solución de distintos problemas de índole local, regional y nacional, al propiciar la generación, aplicación y transferencia del conocimiento efectivo a las necesidades reales que demandan atención para el desarrollo sostenible de nuestra sociedad (Alcántar y Arcos, 2009; García et al., 2018). Esto es tan solo una muestra de la relevancia que implica estudiar el desempeño organizacional, precisamente en el contexto de la educación superior, para contribuir desde la academia en mejorar los resultados en el mediano plazo del desempeño educativo a nivel superior en las diferentes IES del país.

\section{La satisfacción laboral del capital humano en el desempeño de la educación superior}

Cantón y Téllez (2016) subrayan la importancia de analizar la satisfacción laboral en el ámbito educativo, por las implicaciones que tiene en el desempeño de los docentes, puesto que incide de forma directa en la eficacia de su profesión y rendimiento (Anaya y López, 2015; Spector, 1985). Desde la perspectiva de la teoría de las necesidades sociales, la satisfacción se desarrolla en 


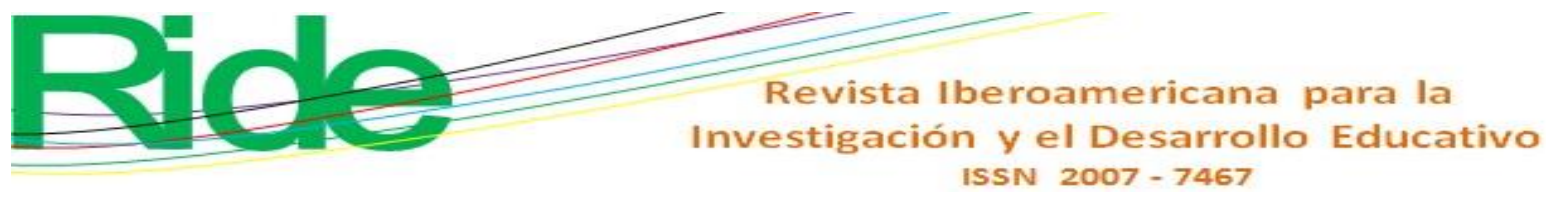

función del grado en que las expectativas personales están cubiertas por la situación laboral (Cantón y Téllez, 2016), lo que genera emociones en el empleado. Esto indudablemente representa un tema complejo en la gestión del capital humano, pero, de una u otra forma, la gerencia educativa requiere analizar esos sentimientos a efecto de propiciar y mantener entornos de trabajo positivos y favorecedores para los docentes (Hernández y Ramos, 2018).

La satisfacción laboral representa un estado emocional, producto de la apreciación que los empleados se forman acerca de qué tanto sus puestos de trabajo y las organizaciones en donde prestan sus servicios les proporcionan estímulos que cubren sus necesidades y expectativas a cambio de lo que ellos aportan a la organización; así, se genera una relación afectiva o estado emocional hacia el trabajo que se refleja en el gusto por lo que hace (Anaya y López, 2015; Cernas, Mercado y Davis, 2018; González et al., 2014; Locke, 1969; Lupano y Castro, 2018; Rodríguez et al., 2011). De acuerdo con Spector (1985), es un constructo que refiere al grupo de actitudes de los empleados que se forma a partir de la valoración que hacen de factores como las remuneraciones, las prestaciones complementarias, los compañeros de trabajo, el ambiente laboral, la comunicación y supervisión y los estándares de trabajo, solo por mencionar algunos aspectos que habrán de contribuir en la satisfacción favorable de los empleados de una organización (Nahid, 2012; Taliadorou y Pashiardis, 2015).

En este sentido, es de suponer que si los trabajadores perciben que a cambio de sus esfuerzos reciben reconocimientos tangibles e intangibles por su desempeño, se presume un estado emocional adecuado y de satisfacción laboral, lo que se traduce en una actitud positiva en la ejecución de sus funciones y responsabilidades, y ello, a la vez, se reflejará en su rendimiento y en los servicios que proporcionan a los usuarios de la institución, puesto que se prevé que su estado emocional positivo se traduzca en un mejor servicio al cliente final, que en el contexto educativo son los estudiantes (Hernández y Ramos, 2018; Rodríguez et al., 2011; Spector, 1985). Sin embargo, hay que tener cuidado respecto a dicho constructo, puesto que, como es resultado de las emociones de la persona, implica una agrupación de sentimientos capaces de producir cambios psicológicos, que determinan el comportamiento y pensamiento de los trabajadores en la organización (Hernández y Ramos, 2018)

De allí el interés de considerar en el alcance de este estudio contemplar como una de las variables explicativas del desempeño educativo en las IES analizadas precisamente a la satisfacción laboral, y a partir de ello reconocer que existen factores que tienden también a explicar o determinar 


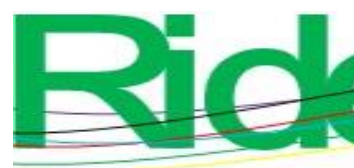

Revista Iberoamericana para la Investigación y el Desarrollo Educativo

ISSN $2007-7467$

la satisfacción de los docentes, como son los referentes al género, salario, tipo de escuela (pública o privada), edad, experiencia docente, entre otros (Nahid, 2012). Por lo que hay que tener presente que la satisfacción o insatisfacción de los docentes puede ser generada o afectada por la ausencia o falta de autonomía en su trabajo, por los cambios y reformas escolares, debido a la imagen pública que se tiene de los profesores, la falta de recursos para desempeñarse, la paga de un sueldo percibido como injusto, el estilo de liderazgo que ejercen los directivos, entre otros indicadores que afectan este estado emocional del personal de una organización (Taliadorou y Pashiardis, 2015). En relación con la satisfacción laboral se ha determinado que esta se relaciona positiva y significativamente con el rendimiento o productividad (Cernas et al., 2018; Lupano y Castro, 2018; Rodríguez et al., 2011).

\section{El compromiso organizacional del capital humano en el desempeño educativo de nivel superior}

Otra de las variables que se propone estudiar en esta investigación hace referencia al compromiso organizacional. Cabe enfatizar que se pensó en ese constructo por la importancia que refleja la entrega e identidad de los empleados con su organización. Si los trabajadores expresan lealtad y compromiso con sus instituciones, este lazo no solo se estima que reflejará satisfacción laboral, sino que va más allá: estaría mostrando que los empleados se sienten parte de la institución $\mathrm{y}$, por ende, se comprometen hacia el logro de los objetivos organizacionales, puesto que un empleado comprometido es un activo valioso que garantiza, a largo plazo, su permanencia y su aporte hacia la obtención de los resultados organizacionales, porque ha generado sentimientos y un lazo afectivo con su institución (Allen y Meyer, 1996; González et al., 2014).

De acuerdo con Allen y Meyer (1996), el compromiso organizacional es una variable multidimensional que representa el vínculo psicológico entre el trabajador y su organización, lo que posibilita generar lazos entre ambos actores, y en donde si esa unión es fuerte, entonces es muy poco probable que los empleados abandonen a la institución (Allen y Meyer, 1990; Cernas et al., 2018). Entonces, el concepto de compromiso puede interpretarse como "un estado psicológico que caracteriza la relación entre una persona y una organización, la cual presenta consecuencias respecto a la decisión para continuar en la organización o dejarla" (Arias, Varela, Loli y Quintana, 2003,p.16), o bien como "la fuerza con la que un individuo se siente vinculado a una organización y que implica el seguimiento de un curso de acción relevante para la organización” (Chiang, Núnez, 


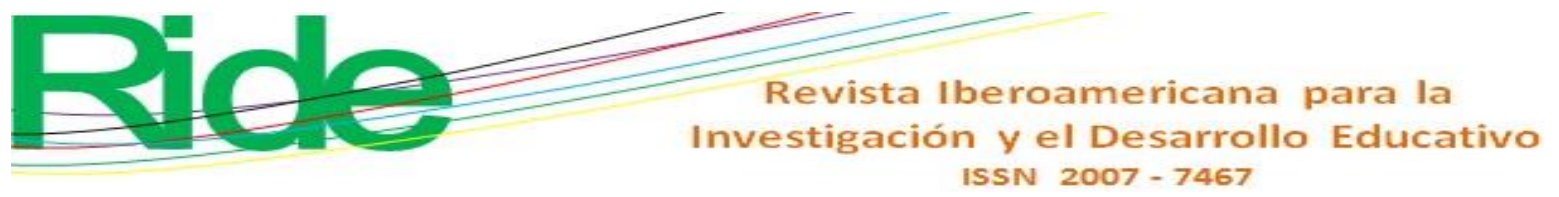

Martín y Salazar, 2010, p.92), por lo que se infiere que entre mayor compromiso organizacional, esto se verá reflejado en la satisfacción laboral y por en ende en el logro de objetivos y rendimiento organizativo (Araya, Figueroa, Grandón, Ramírez y Alfaro, 2018; Cernas et al., 2018; Lupano y Castro, 2018).

Se estima que el personal de las instituciones educativas es responsable de contribuir en la formación de capital humano competitivo para el futuro de una sociedad. Y analizar qué tanto ellos se sienten comprometidos con sus organizaciones es estratégico en nuestros tiempos, puesto que ese estado psicológico entre más fuerte sea, mayor bien en la formación de las competencias de los alumnos tendrá, y así se favorecerá cumplir con las cualificaciones que demanda el mercado laboral. Este estudio es particularmente interesante en concreto por el planteamiento del tema de investigación trazado. Puesto que se relaciona con variables antecedentes para abordar la gestión del capital humano en instituciones educativas. Entre esos factores, Bontis y Serenko (2009) señalan a la satisfacción laboral y el compromiso organizacional como elementos que contribuyen en la administración de los recursos humanos y que pueden favorecer un ambiente de trabajo para el intercambio del conocimiento, lo cual impacta en la retención del personal y su contribución hacia la organización, mediante la capacidad de innovación en los procesos, servicios y productos.

Se ha encontrado en estudios previos que la satisfacción laboral y el compromiso organizacional de los docentes muestran relaciones positivas significativas (Nahid, 2012; Lupano y Castro, 2018). Por ende, es importante gestionar prácticas de recursos humanos que fortalezcan en sus empleados cada vez más; mejores valoraciones de estos constructos, a efecto de que su desempeño contribuya al logro y competitividad de las IES. Como ya se ha mencionado, entre más satisfacción laboral se perciba por los empleados, mayor es su compromiso con la organización, lo cual favorece a generar y compartir conocimientos. También se encuentra que el compromiso organizacional de los trabajadores favorece la retención laboral y el desempeño organizacional (Bontis y Serenko, 2009). De ahí la importancia de analizar ambos constructos, que son la satisfacción laboral y el compromiso organizacional del capital humano, por las relaciones positivas y significativas que se han identificado entre ambas variables (Cernas et al., 2018), además por su asociación con las variables de productividad, bienestar y permanencia de los trabajadores en las organizaciones (Cernas et al., 2018), así como en la consecución de mejores resultados en la rentabilidad y desempeño organizacional (Lupano y Castro, 2018). 


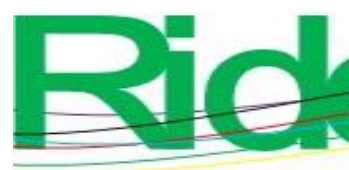

\section{Revista Iberoamericana para la Investigación y el Desarrollo Educativo \\ ISSN $2007-7467$}

En este sentido, este estudio se posiciona en la discusión de la trascendencia de la gestión del capital humano (docentes) para el logro educativo y la mejora continua de la calidad de la educación, por el impacto que ellos tienen en la formación profesional de los estudiantes (Montanares y Junod, 2018), puesto que tienen esa responsabilidad inmediata y, por ende, ello contribuye a gran parte de los resultados educativos en las universidades públicas. El capital humano representa esa dimensión del capital intelectual que implica el conjunto de habilidades, experiencias, conocimientos, aptitudes y actitudes (Bontis, 1998; Bontis, 2001; Bontis y Serenko, 2009), el cual, gestionado de forma efectiva, resulta atractivo para generar un compromiso con los resultados organizacionales. Como otros estudios realizados en diferentes contextos lo indican, este grupo de activos intangibles tiene impactos positivos en el desempeño de las organizaciones (Bontis y Serenko, 2009; Gogan et al., 2016; Hashim et al., 2015; Hussinki et al., 2017).

Por lo que, en el marco de las ideas expuestas en esta sección de literatura, se presenta en seguida el modelo teórico del estudio (figura 1), con las hipótesis de investigación correspondientes:

HI1: La satisfacción laboral se relaciona positiva y significativamente con el desempeño educativo en las IES.

HI2: El compromiso organizacional se relaciona positiva y significativamente con el desempeño educativo en las IES.

HI3: La competencia del capital humano se relaciona positiva y significativamente con el desempeño educativo en las IES.

Figura 1. Modelo teórico de variables explicativas del desempeño educativo en IES

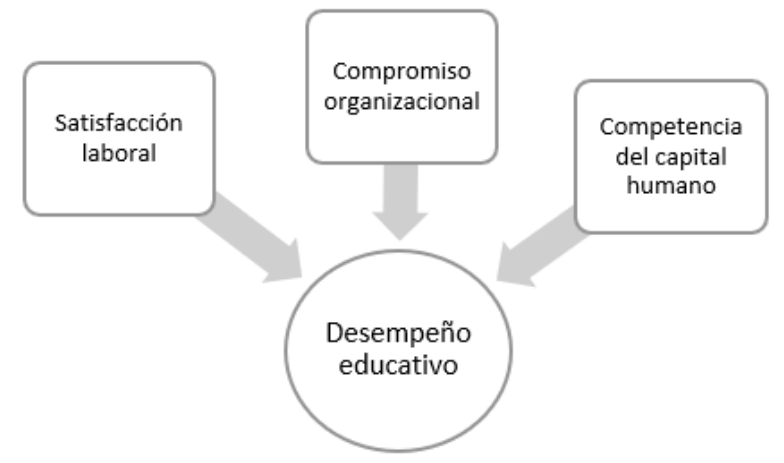

Fuente: Elaboración propia con base en Bontis y Serenko (2009) 


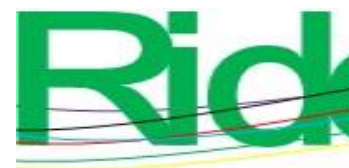

Revista Iberoamericana para la Investigación y el Desarrollo Educativo

ISSN $2007-7467$

\section{Material y método}

Este estudio se desarrolló desde el enfoque cuantitativo, caracterizándose por ser transaccional, no experimental y con alcance explicativo (Hernández, Fernández y Baptista, 2014). Se aplicó un cuestionario a 90 directivos de IES, quienes aceptaron de manera voluntaria participar en la investigación (muestra a conveniencia). Debido a la falta de respuesta en diversas preguntas del cuestionario, que representaban más de 30 \% (Hinkin, 1995), se eliminaron seis. Por lo tanto, la muestra no probabilística fue de 84 encuestados. Se decidió utilizar el cuestionario como medio para recoger datos, con motivo de que es la técnica recurrente en la medición de aspectos abstractos como el clima organizacional, la satisfacción laboral, las competencias del capital humano y su incidencia en el desempeño organizacional (Zenteno Hidalgo y Durán, 2016).

En el diseño del cuestionario se contemplaron cinco apartados enfocados en recoger datos de las cuatro variables objeto de estudio, y una sección que se destinó para recabar información general de los encuestados y de sus instituciones (puesto, antigüedad en el mismo, el género, la edad, la escolaridad, el sector público o privado de la IES). La recolección de la información se llevó a cabo en el periodo de marzo a junio del 2019, previo a solicitud oficial presentada a las autoridades directivas; fueron requeridas varias visitas para aplicar el cuestionario al personal que voluntariamente decidió responder el instrumento.

En relación con la validez de contenido, se precisa que el cuestionario diseñado para este estudio se fundamentó en la revisión de estudios teóricos y empíricos previos sobre las cuatro variables de interés (Bontis, 1998; Bontis, 2001; Bontis y Serenko, 2009; Hernández, Méndez y Contreras, 2014; Pedraza, 2018), los cuales representaron el referente básico para elaborar y posteriormente validar las escalas de compromiso organizacional, satisfacción laboral, capital humano y desempeño organizacional (tabla 1).

Con los datos recabados, se utilizó la estadística descriptiva (medias, porcentajes) para exponer las principales características de los encuestados y de sus IES, así como para describir la apreciación de los indicadores de las variables independientes y dependiente del modelo de estudio. Para efecto de validar las hipótesis de esta investigación, que establecían relaciones positivas y significativas entre las variables independientes (clima organizacional, satisfacción laboral, capital humano) y la variable dependiente de desempeño organizacional en las IES analizadas, se aplicó, con fundamento en Ruíz, Pardo y San Martín (2010), el modelado de ecuaciones estructurales (SEM, por sus siglas en inglés), mediante la técnica de mínimos cuadrados parciales (PLS, también 


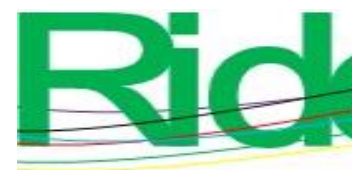

Revista Iberoamericana para la

Investigación y el Desarrollo Educativo

ISSN $2007-7467$

por sus siglas en inglés) por su potencia para estudiar varias relaciones de forma simultánea entre variables (Martínez y Fierro, 2018).

Tabla 1. Medición de las variables de interés

\begin{tabular}{|l|c|l|l|}
\hline \multicolumn{1}{|c|}{ Variables } & Preguntas & \multicolumn{1}{|c|}{ Escala } & \multicolumn{1}{c|}{$\begin{array}{c}\text { Referentes para } \\
\text { fundamentar el diseño de } \\
\text { medición }\end{array}$} \\
\hline $\begin{array}{l}\text { Satisfacción laboral (VI) } \\
\begin{array}{l}\text { Compromiso } \\
\text { organizacional (VI) } \\
\text { Capital humano (VI) }\end{array}\end{array}$ & 8 & $\begin{array}{l}\text { Tipo Likert, que va } \\
\text { de uno (nunca) a } \\
\text { cinco (siempre) }\end{array}$ & $\begin{array}{l}\text { (Allen y Meyer, 1990; Allen } \\
\text { y Meyer, 1996; Anaya y } \\
\text { López, 2015; Bontis, 2001; } \\
\text { Bontis y Serenko, 2009; } \\
\text { Cantón y Téllez, 2016; } \\
\text { Hernández } \text { et al., 2014; } \\
\text { Pedraza, 2018) }\end{array}$ \\
\hline $\begin{array}{l}\text { Desempeño } \\
\text { educativo (VD) }\end{array}$ & 11 & $\begin{array}{l}\text { Tipo Likert, que va } \\
\text { de uno (pésimo) a } \\
\text { cinco (superior) }\end{array}$ & $\begin{array}{l}\text { (Bontis, 1998; Bontis, 2001; } \\
\text { Bontis } \text { et al., 2000; Bontis y } \\
\text { Serenko, 2009; Gogan } \text { et al., } \\
\text { 2016; Hashim } \text { et al., 2015) }\end{array}$ \\
\hline
\end{tabular}

Nota: VI = Variable independiente; VD = Variable dependiente.

Fuente: Elaboración propia con base en los autores en la tabla citados

La ventaja de SEM es que permite estudiar el efecto de diversas variables independientes sobre otra dependiente (análisis multivariante); por lo que, para esta investigación, la técnica aplicada fue la de PLS, como ya se mencionó, con base en el objetivo general de indagación que ha sido estudiar precisamente la complejidad de las relaciones con métodos de reconocida potencia estadística (Martínez y Fierro, 2018), y en particular debido al tamaño de muestra y la medición ordinal de las variables, como es el caso del presente análisis (Hair, Hult, Ringle y Sarstedt, 2014; Mondéjar, 2017). En la aplicación de esta técnica se utilizó el software Smart PLS versión 3.8.2.

Con el SEM se busca analizar en el modelo de medida reflexivo (externo) y las cargas factoriales de los indicadores en relación con su variable latente, además de estudiar los criterios de fiabilidad, validez convergente y discriminante; en tanto que en el modelo estructural (interno) se evalúan las relaciones causales entre las variables exógenas (independientes) y endógenas (dependientes), considerando los valores $t$ y $p$ de las relaciones, y la potencia de la predicción con el coeficiente $r 2$ (Gómez, 2011; Hair et al., 2014). 


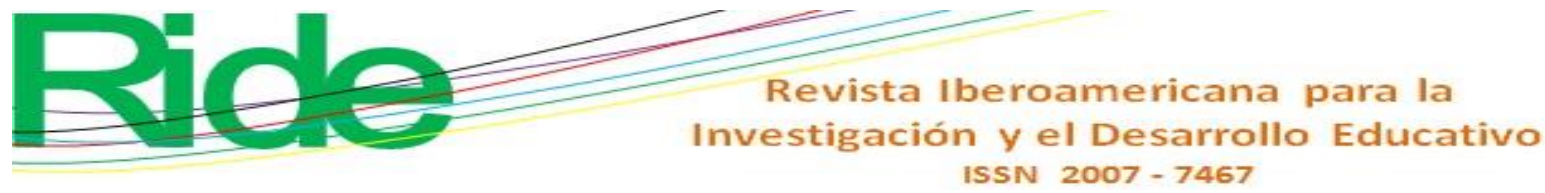

Resultados

\section{Explorando la relación predictiva de prácticas de gestión del capital humano con el desempeño educativo}

Se observó que de la totalidad de los encuestados en las IES que accedieron participar en el presente estudio, $45.2 \%$ son hombres y $54.8 \%$ son mujeres. La mitad de los encuestados ocupa el puesto de docente, mientras que el resto desempeña actividades de gestión administrativa y académica en sus instituciones, por lo que se determina una participación equilibrada de ambos roles en la organización. Además, la gran mayoría de los encuestados (60 \%) tiene más de cinco años de antigüedad en la IES donde presta sus servicios; o lo que es lo mismo, solo $40 \%$ de ellos tiene menos de ese tiempo en sus organizaciones educativas. Respecto a la edad de los encuestados, se identificó que un porcentaje bajo (8.3\%) tienen entre 18 a 33 años; la gran mayoría de ellos tiene más de 34 años de edad (91.70\%).

Se encontró también que $15.5 \%$ cuenta solo con estudios de licenciatura, mientras que la gran mayoría tienen escolaridad de posgrado (84.5\%). Las instituciones educativas donde prestan sus servicios los empleados encuestados corresponden con $75 \%$ al sector público y con $25 \%$ al ámbito privado. En relación con el número de años en que las IES operan en el mercado educativo, se observó que la mayoría tienen más de 10 años prestando sus servicios a la comunidad educativa $(89.3 \%)$ y solo un porcentaje menor tiene menos de esa cantidad con su oferta educativa a la sociedad (10.7\%). Cabe señalar que $14.3 \%$ de las IES están ubicadas en la zona norte del estado de Tamaulipas y $85.7 \%$ en el centro de esta entidad federativa del país.

Una vez analizados los datos descriptivos de los encuestados y de sus instituciones, se pasó a la valoración del modelo de medida en el presente estudio, paso necesario para determinar la fiabilidad y validez de los constructos implicados. Se calculó los indicadores pertinentes de confiabilidad, que son el alfa de Cronbach y la fiabilidad compuesta (ambos mínimo 0.70) y de validez convergente, que es la varianza extraída media (mínimo 0.50). Se verificaron valores aceptables para las cuatro variables latentes, tal y como puede observarse en la tabla 2 , en donde los índices de consistencia interna (alfa de Cronbach y fiabilidad compuesta) se localizan arriba del valor aceptable (0.70); también se da cumplimiento con la validez convergente, puesto que la varianza extraída media (AVE) en todas las variables superó el mínimo de 0.50 . 


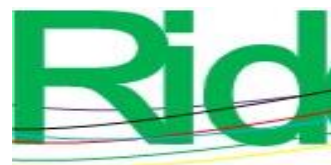

Revista Iberoamericana para la Investigación y el Desarrollo Educativo

ISSN $2007-7467$

Tabla 2. Indicadores de fiabilidad y validez convergente del modelo de medida

\begin{tabular}{|l|c|c|c|}
\hline Constructos & $\begin{array}{l}\text { Alfa de } \\
\text { Cronbach }\end{array}$ & $\begin{array}{c}\text { Fiabilidad } \\
\text { compuesta }\end{array}$ & AVE \\
\hline Capital humano & 0.935 & 0.945 & 0.632 \\
\hline Compromiso organizacional & 0.865 & 0.907 & 0.711 \\
\hline Satisfacción laboral & 0.881 & 0.913 & 0.677 \\
\hline Desempeño educativo & 0.953 & 0.958 & 0.622 \\
\hline
\end{tabular}

Fuente: Elaboración propia

Para la validez discriminante del modelo de medida, se aplicó el criterio de Fornell-Larcker, el cual establece que los valores de la diagonal principal (raíz cuadrada de la AVE), respecto a las correlaciones de las variables del modelo, muestran índices en todos los casos mayores al resto de los valores de la columna correspondiente (Hair et al., 2014). De esta forma, se observa que se cumple con este indicador de validez en la tabla 3.

Tabla 3. Validez discriminante del modelo de medida

\begin{tabular}{|l|c|c|l|l|}
\hline Constructos & $\begin{array}{l}\text { Capital } \\
\text { humano }\end{array}$ & $\begin{array}{l}\text { Compromiso } \\
\text { organizacional }\end{array}$ & $\begin{array}{l}\text { Desempeño } \\
\text { educativo }\end{array}$ & $\begin{array}{l}\text { Satisfacción } \\
\text { laboral }\end{array}$ \\
\hline Capital humano & 0.795 & & & \\
\hline $\begin{array}{l}\text { Compromiso } \\
\text { organizacional }\end{array}$ & 0.484 & 0.843 & & \\
\hline Satisfacción laboral & 0.732 & 0.488 & 0.789 & \\
\hline Desempeño educativo & 0.662 & 0.581 & 0.761 & 0.823 \\
\hline
\end{tabular}

Fuente: Elaboración propia

Una vez que se efectúo el análisis del modelo de medida esquematizado en el gráfico de ruta (figura 2), se procedió a validar las hipótesis planteadas. Cabe precisar que varios reactivos fueron eliminados en las tres variables independientes, ya que no lograron una carga factorial igual o superior a 0.70 (Hair et al., 2014). Por ejemplo, en capital humano quedó fuera el reactivo CH1 ("En esta organización los empleados expresan nuevas ideas para mejorar los procesos y servicios"); de la variable de compromiso organizacional se fue el CO1 ("Siento como si los problemas de esta organización fueran míos"); mientras que de la satisfacción laboral se fueron tres reactivos, a saber, SL1 ("Libertad para elegir su propio método de trabajo"), SL7 ("Variedad 

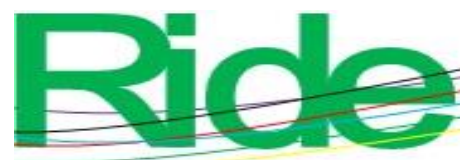

Revista Iberoamericana para la

de tareas que realizan en su trabajo") y SL8 ("Estabilidad en el empleo"). De la variable desempeño educativo no se eliminó ninguno reactivo: se conservaron los 14 diseñados para medir este constructo. Posterior a la valoración de la calidad del modelo de medida, se transitó a la segunda fase del proceso de análisis, que consistió en la valoración del modelo estructural (Gómez, 2011; Hair et al., 2014). Para esto se tomaron en cuenta los siguientes aspectos: 1) evaluar la significancia estadística de las hipótesis (bootstrapping), definiendo variables estadísticamente significativas (tabla 4) cuando el estadístico $T$ es mayor a $1.96^{1} ; 2$ ) precisión de las predicciones (indicador $r 2$ ); 3) tamaño de los efectos $f 2$, y 5) la relevancia predictiva del modelo mediante el estadístico $q 2$. Para esta investigación, el valor de $r 2$ es considerado bueno e indica que el desempeño educativo en las IES estudiadas es explicado en $67 \%$, como se identifica en la figura 2.

Figura 2. Modelo explicativo del desempeño educativo en IES analizadas

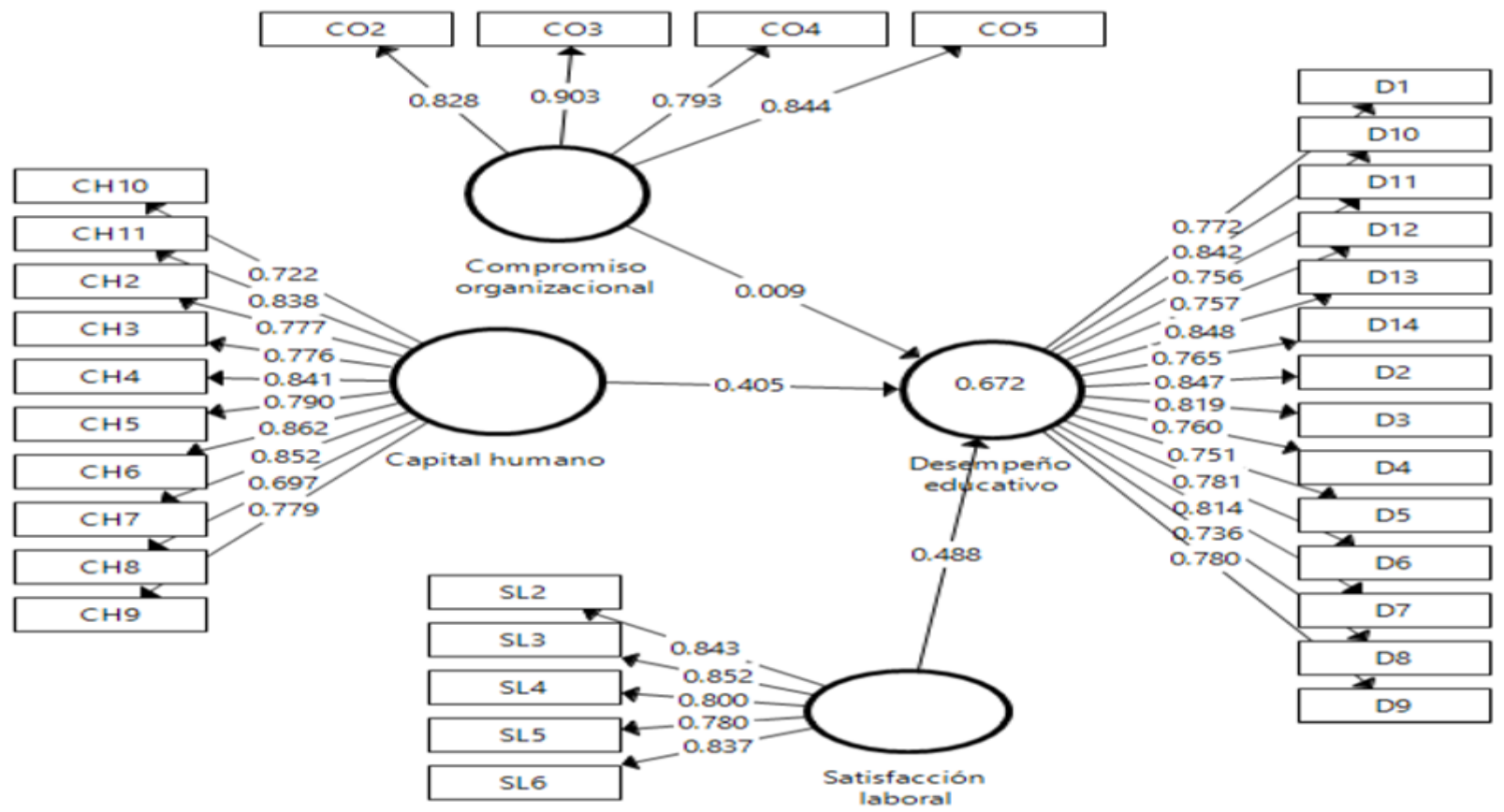

Fuente: Elaboración propia

\footnotetext{
${ }^{1} \mathrm{Si}$ los valores de $t$ son mayores de 1.96 , conlleva a valores de $p$ menores de $0.05 \mathrm{y}$, por lo tanto, serían significativos a $0.05 \%$ (95\% de confianza). Si los valores de $t$ son mayores de 2.56, indican significancia al 0.01 (99\% de confianza) e incluso si son mayores a 1.645, lo son al nivel de 0.10 (90\% de confianza).
} 


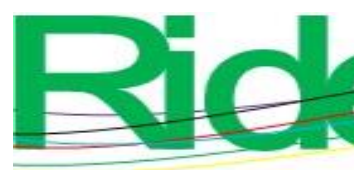

\section{Revista Iberoamericana para la Investigación y el Desarrollo Educativo \\ ISSN $2007-7467$}

En la tabla 4, por su parte, se puede observar que, con base en los resultados generados con el procedimiento de bootstrapping, solo dos de las tres hipótesis planteadas en esta investigación son aceptadas (HI1 y HI3), y que, consecuentemente, únicamente la satisfacción laboral y el capital humano tienden a explicar el desempeño educativo en la IES analizadas. Respecto al compromiso organizacional, no se confirma que sea una variable explicativa del desempeño en el presente estudio (el valor $p$ fue mayor que 0.10 ).

Tabla 4. Valores $t$ y $p$ para validar hipótesis de la relación del capital humano, satisfacción laboral y compromiso organizacional con el desempeño educativo en las IES

\begin{tabular}{|l|l|c|c|l|}
\hline Hipótesis & \multicolumn{1}{|c|}{ Relaciones } & Valor & Valor & Hipótesis \\
\hline HI1 & $\begin{array}{l}\text { Satisfacción laboral -> } \\
\text { Desempeño educativo }\end{array}$ & 5.61 & 0.000 & Se acepta \\
\hline HI2 & $\begin{array}{l}\text { Compromiso } \\
\text { organizacional -> } \\
\text { Desempeño educativo }\end{array}$ & 0.09 & 0.92 & No se acepta \\
\hline HI3 & $\begin{array}{l}\text { Capital humano -> } \\
\text { Desempeño educativo }\end{array}$ & 4.277 & 0.000 & Se acepta \\
\hline
\end{tabular}

Nota: HI1: Hipótesis de investigación.

Fuente: Elaboración propia

Posteriormente, una vez que se determinó que solo dos de las variables explicativas tienden a mostrar una relación positiva y significativa hacia el desempeño en las IES analizadas, se procedió a mostrar la valoración que hacen los encuestados de los aspectos considerados en cada una de las variables de capital humano, satisfacción laboral y el desempeño educativo. De manera general, se encontró que, siguiendo la percepción de los encuestados, valoran de manera favorable en sus instituciones los aspectos de los tres constructos, puesto que sus medias generales estuvieron en el nivel 4 (capital humano = 4.05; satisfacción laboral $=4.14$, desempeño educativo $=4.10$ ).

De manera específica, se observó que en el constructo de capital humano todos valoran de manera positiva los aspectos de que los empleados cuenten con experiencia, mejoren sus habilidades y conocimientos constantes, cuenten con las competencias para su puesto, que sean los mejores del sector, que den su mejor esfuerzo, que aprendan de los demás, que tengan la 

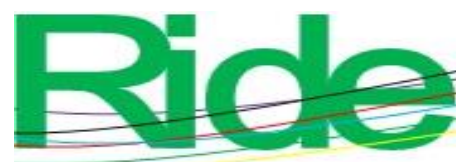

Revista Iberoamericana para la

Investigación y el Desarrollo Educativo

ISSN $2007-7467$

oportunidad de expresarse con libertad, que den su máximo rendimiento y tienen en alta estima el equipo porque se fomenta la confianza y la colaboración (figura 3). De allí la relevancia de seguir fortaleciendo estrategias que contemplen estos aspectos en las prácticas de gestión de recursos humanos por la gerencia educativa.

Figura 3. Valoración de los aspectos del constructo de capital humano desde la percepción de los encuestados

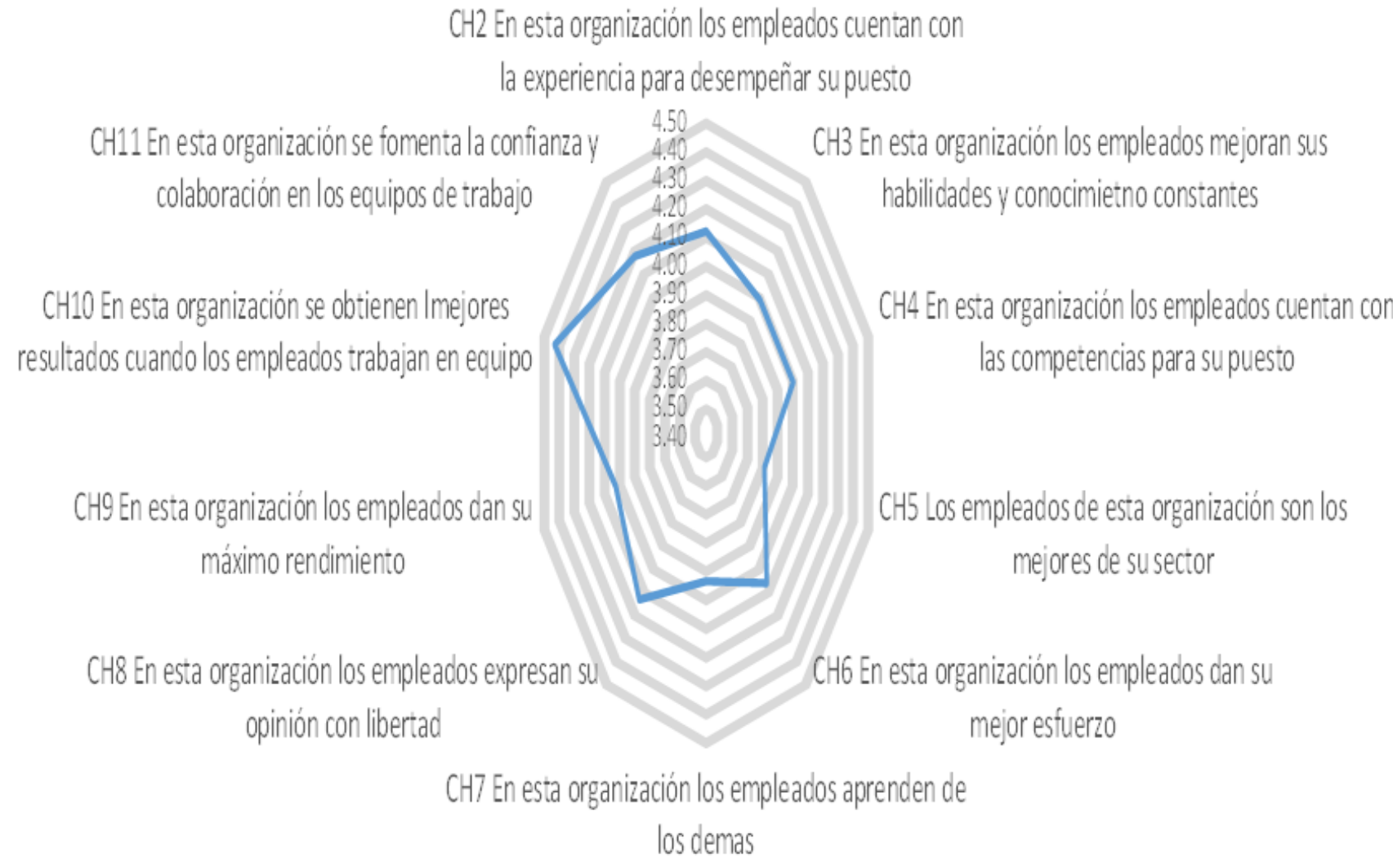

Fuente: Elaboración propia

En relación con la variable de satisfacción laboral, se identificó que los aspectos valorados por los encuestados precisan prácticas de gestión del personal que los directivos de las IES debiesen tomar en cuenta, porque representan indicadores muy bien calificados por los encuestados. Por ejemplo, se mencionan los aspectos de proporcionar reconocimiento por el trabajo bien hecho, la responsabilidad por las tareas asignadas, la posibilidad de utilizar sus capacidades en el desempeño de su trabajo, las posibilidades de crecimiento en la organización y la atención de la dirección acerca de las sugerencias que ellos presentan; todos evaluados favorablemente, tal y como puede observarse en la figura 4. 


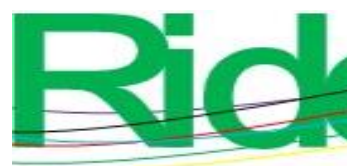

Revista Iberoamericana para la Investigación y el Desarrollo Educativo

ISSN $2007-7467$

Figura 4. Valoración de los aspectos del constructo de satisfacción laboral

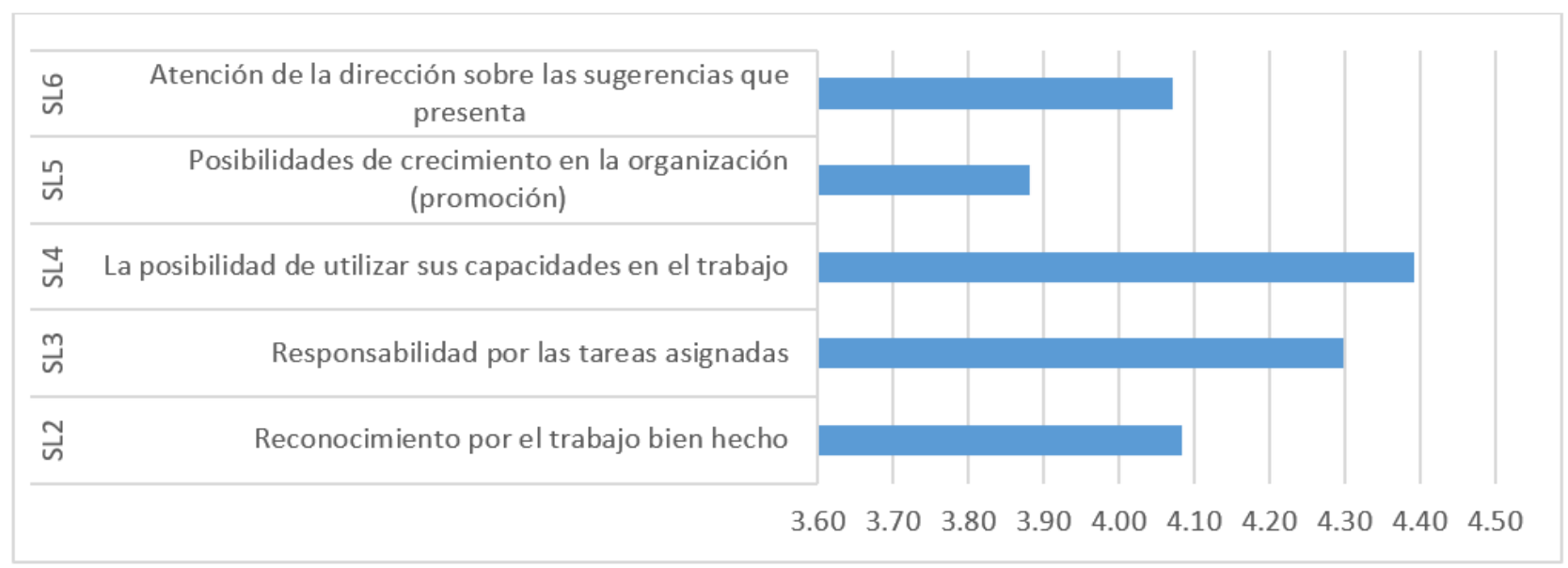

Fuente: Elaboración propia

Respecto al constructo del desempeño educativo, los administrativos y docentes encuestados calificaron también de manera favorable los resultados que ellos aprecian del desempeño de su institución, puesto que los 14 aspectos escudriñados se encontraron en medias de cuatro sobre la base de la escala Likert que se les mostró para emitir su evaluación, lo cual puede observarse en la tabla 5 a detalle. Entre los resultados descriptivos a destacar están la importancia otorgada en materia de desempeños en los aspectos de imagen institucional, calidad de los procesos y servicios, la formación de calidad de los alumnos, la consecución de objetivos e indicadores académicos y un factor que es de interés actualmente, el referente a la vinculación de las IES con el sector productivo y la sociedad en general. 


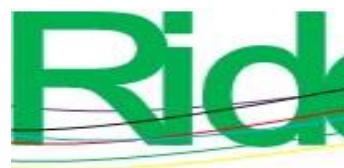

Revista Iberoamericana para la Investigación y el Desarrollo Educativo

ISSN $2007-7467$

Tabla 5. Valoración del desempeño educativo en las IES analizadas

\begin{tabular}{|l|l|c|}
\hline Reactivo & \multicolumn{1}{|c|}{ Descripción } & Media \\
\hline D1 & Imagen de la institución y servicios & 4.27 \\
\hline D2 & $\begin{array}{l}\text { Calidad académica de los procesos y servicios educativos } \\
\text { proporcionados }\end{array}$ & 4.35 \\
\hline D3 & Formación de calidad de los estudiantes & 4.24 \\
\hline D4 & Valor añadido a los procesos y servicios otorgados & 4.07 \\
\hline D5 & $\begin{array}{l}\text { Satisfacción de los usuarios con los procesos y servicios } \\
\text { proporcionados }\end{array}$ & 4.11 \\
\hline D6 & Logro de objetivos e indicadores académicos alcanzados & 4.17 \\
\hline D7 & Calidad en los procesos servicios proporcionados & 4.23 \\
\hline D8 & Nivel de tecnología incorporados en los procesos- & 4.08 \\
\hline servicios educativos & 3.98 \\
\hline D9 & Productividad de los empleados & 3.96 \\
\hline D10 & Eficiencia en procesos y actividades de gestión & 3.99 \\
\hline D11 & Aplicación de los recursos públicos & 3.94 \\
\hline D12 & Mejora en la coordinación de procesos internos & \\
\hline D13 & Innovación continua en los procesos servicios educativos & 3.99 \\
\hline D14 & $\begin{array}{l}\text { Vinculación con el sector productivo y sociedad en } \\
\text { general }\end{array}$ & \\
\hline & & \\
\hline
\end{tabular}

Fuente: Elaboración propia

\section{Discusión}

Se ha observado con los resultados del presente estudio que los aspectos intangibles son valorados en las prácticas de gestión de personal, y que tienen efectos positivos sobre el desempeño de las organizaciones en general (figura 2). Con el modelado de ecuaciones estructurales, se confirmó que las variables latentes de satisfacción laboral y las competencias del capital humano tienen relaciones positivas y significativas con el desempeño en las IES analizadas. 


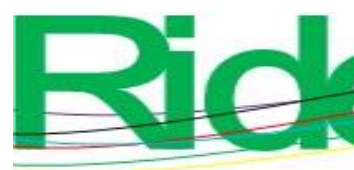

Revista Iberoamericana para la Investigación y el Desarrollo Educativo

ISSN $2007-7467$

Los hallazgos, como tal, son evidencia empírica que permiten confirmar lo ya dicho en la literatura: la satisfacción laboral tiende a influir en el desempeño laboral y organizacional de las entidades; tal relación predictiva se confirma en la presente investigación (Anaya y López, 2015; Cantón y Téllez, 2016; Cernas et al., 2018; González et al., 2014; Lupano y Castro, 2018; Rodríguez et al., 2011)

Así, pues, como también se ha dicho en estudios previos, el capital humano es un componente clave del capital intelectual (Bontis, 2001), el cual tiende a explicar o contribuir en los resultados organizacionales (Bontis,1998; Bontis, 2001; Bontis y Serenko, 2009; Gogan et al., 2016; Hashim et al., 2015; Hussinki et al., 2017). En ese sentido, esta hipótesis también se acepta en el presente análisis, lo cual aporta evidencia empírica desde el contexto de la educación superior. En la presente investigación se observa que, desde la percepción de los directivos encuestados, las competencias del personal de sus universidades influyen en el logro de sus indicadores académicos.

Algo interesante, y al mismo tiempo contrastante, y que tiene que ver con la hipótesis referente a que el compromiso organizacional contribuye a explicar el desempeño educativo, fue que se determinó que no existe una relación significativa entre ambos constructos; sin embargo, es una evidencia empírica que aporta un sentido de interés para llevar a cabo investigaciones de naturaleza cualitativa, a fin de comprender más este fenómeno que en la literatura se estima valioso y como parte de las prácticas que hay que fomentar en la gestión directiva del capital humano (Allen y Meyer,1990, 1996; Lupano y Castro, 2018), por su contribución a la identidad y pertenencia con la organización, pero que no se observó como una variable que contribuye a explicar el desempeño en las IES analizadas, lo cual contrasta con el supuesto de que el compromiso de los empleados contribuye al desempeño de las organizaciones.

\section{Conclusiones e implicaciones del estudio}

Como docentes se tiene la gran responsabilidad en el sistema de educación superior de formar capital humano altamente competitivo a fin de lograr su inserción pertinente en el mercado laboral y en la contribución que habrán de hacer para el desarrollo de la sociedad. Ello implica estudiar hacia el interior de las organizaciones educativas los diversos fenómenos que afectan su desempeño y efectividad. Ante este reto, y por la misión clave que tienen las universidades en la sociedad, resulta fundamental conocer si estas entidades educativas gestionan eficazmente sus recursos y capacidades; en este caso, los activos intangibles que poseen en la forma de 


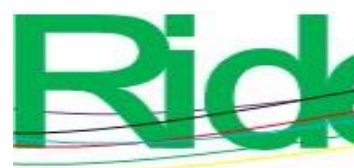

Revista Iberoamericana para la Investigación y el Desarrollo Educativo

ISSN $2007-7467$

conocimientos, competencias, experiencia de su capital humano; y si movilizan ambientes de trabajo que fortalecen la satisfacción laboral y el compromiso organizacional para que, administrando efectivamente esos activos intangibles, cuenten con desempeños superiores y valor agregado en sus procesos, productos y servicios educativos que proporcionan a los estudiantes y a la sociedad en general.

De ahí que el interés principal de esta investigación ha sido contribuir desde la academia a seguir aportando conocimiento, desde otros contextos y unidades de análisis, sobre el fenómeno del capital intelectual, concretamente en el componente del capital humano, así como de prácticas de administración de personal (satisfacción laboral y compromiso organizacional) y su contribución al desempeño organizacional. A efecto de que los gerentes de las organizaciones educativas mexicanas, y en específico las localizadas en Tamaulipas, visualicen el valor de los activos intangibles, con la finalidad de romper el paradigma tradicional que impera sobre la medición del rendimiento o desempeño de las organizaciones a partir exclusivamente de indicadores financieros. Por ello, resulta necesario ahondar en la comprensión y especialización del objeto de estudio, a fin de que mejoren la gestión de sus prácticas de recursos humanos en bien de sus propias organizaciones, pero fundamentalmente en beneficio de la formación de calidad de los alumnos y de su vinculación efectiva con la sociedad.

En esta investigación se hizo el planteamiento de tres hipótesis relacionadas con prácticas de gestión de personal, que hacen referencia a variables que se estiman importantes para que los empleados se desarrollen en ambientes de trabajo idóneos, considerando entre esos temas de interés a la satisfacción laboral, el compromiso organizacional y las competencias del capital humano como factores intangibles que finalmente puedan incidir en el desempeño de las organizaciones.

En ese marco de hipótesis, se logró observar en el presente estudio que solamente la satisfacción laboral y la competencia del capital humano mostraron una relación positiva y significativa con el desempeño en la IES analizadas. Esto debe ser tomado en cuenta principalmente por los directivos de las escuelas de educación superior analizadas, ya que, tal y como se discutió en este artículo, el capital humano es el componente central del capital intelectual, porque el conocimiento, la experiencia, habilidades y demás saberes son propiedad de los empleados, y si ellos dejan de permanecer en la organización, su know how se va con ellos. De allí la relevancia de diseñar e implementar estrategias efectivas de administración de los recursos humanos que fomenten y fortalezcan ambientes laborales propicios para generar satisfacción 


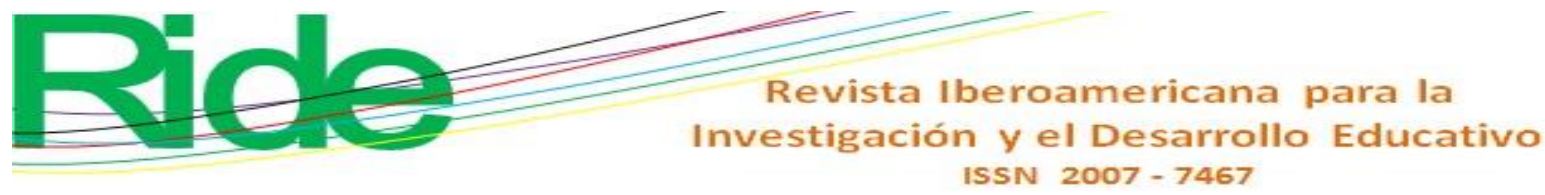

laboral. También de allí la relevancia de que las organizaciones se interesen por establecer las estrategias para captar el conocimiento tácito de los trabajadores, a fin de documentarlo, socializarlo y gestionarlo estratégicamente para convertirlo en su propiedad.

\section{Agradecimientos}

Un sincero agradecimiento a los directivos y docentes de las IES públicas y privadas de la zona centro y norte del estado de Tamaulipas, México, que accedieron voluntariamente participar en la presente investigación.

\section{Referencias}

Alcántar, V. M., \& Arcos, J. L. (2009). La vinculación como factor de imagen y posicionamiento de la Universidad Autónoma de Baja California, México, en su entorno social y productivo. Revista Electrónica de Investigación Educativa, 11(1), 2-20. Obtenido de http://redie.uabc.mx/vol11no1/contenidoalcantar2.

Allen, N. J., \& Meyer, J. P. (1990). The measurement and antecedents of affective, continuance and normative commitment to the organization. Journal of Occupational Psychology, 63, 301-320. doi:http://dx.doi.org/10.1111/j.2044-8325.1990.tb00506.x

Allen, N. J., \& Meyer, J. P. (1996). Affective, Continuance, and Normative Commitment to the Organization: An Examination of Construct Validity. Journal of Vocational Behavior, 49, 252-276. doi:https://doi.org/10.1006/jvbe.1996.0043

Anaya, D., \& López, E. (2015). Satisfacción laboral del profesorado de educación secundaria. Revista de Investigación Educativa, 33(2), 435-452. doi:https://doi.org/10.6018/rie.33.2.202841

Araya, S., Figueroa, P., Grandón, E., Ramírez, P., \& Alfaro, J. (2018). Explorando la relación Sistemas de Información y Rendimiento Organizativo, a través de la Satisfacción y Compromiso Laboral en Universidades. Iberian Conference on Information Systems and Technologies, CISTI, (págs. 1-4). doi:DOI: 10.23919/CISTI.2018.8399172

Arias, F., Varela, D., Loli, A., \& Quintana, M. (2003). El compromiso organizacional y su relación con algunos factores demográficos y psicológicos. Revista de Investigación en Psicología, 6(2), 13-25. 


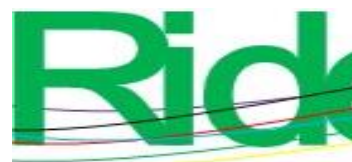

Revista Iberoamericana para la

Investigación y el Desarrollo Educativo

ISSN $2007-7467$

Bontis, N. (1998). Intellectual capital: an exploratory study that develops measures and models. Management Decision, 36(2), 63-76. Obtenido de http://citeseerx.ist.psu.edu/viewdoc/download?doi=10.1.1.24.9765\&rep=rep1\&type=pdf

Bontis, N. (2001). Assessing knowledge assets: a review of the models used to measure intellectual capital. International Journal of Management Reviews, 3(1), 41-60. Obtenido de http://citeseerx.ist.psu.edu/viewdoc/download?doi=10.1.1.112.8365\&rep=rep1\&type=pdf

Bontis, N., \& Serenko, A. (2009). A causal of human capital antecedents and consequents in the financial services industry. Journal of Intellectual Capital, 10(1), 53-69. doi:https://doi.org/10.1108/14691930910922897.

Bontis, N., Chua Chong Keow, W., \& Richardson, S. (2000). Intellectual capital and business performance in Malaysian industries. Journal of Intellectual Capital, 1, 85-100. doi:https://doi.org/10.1108/14691930010324188

Budovich, L., \& Nadtochiy, Y. (2019). Teacher intellectual capital. Assessment approaches.

$\begin{array}{llll}\text { Revista } & \text { Espacios, } & \text { 2-27. } & \text { Obtenido }\end{array}$

https://www.scopus.com/record/display.uri?eid=2-s2.0-

$85064767409 \&$ origin $=$ resultslist $\&$ sort $=$ plf-

$\mathrm{f} \& \mathrm{src}=\mathrm{s} \& \mathrm{st} 1=$ intelectual+capital+\&st2=\&sid=36f5a8dcc8160feec $1 \mathrm{cc} 1 \mathrm{f} 6 \mathrm{a} 509 \mathrm{~b} 6780 \&$ sot $=$ $\mathrm{b} \& \mathrm{sdt}=\mathrm{b} \& \mathrm{sl}=35 \& \mathrm{~s}=\mathrm{TITLE}-\mathrm{ABS}-$

KEY\%28intelectual+capital+\%29\&relpos=0\&citeCnt=0\&searchT

Cantón, I., \& Téllez, S. (2016). La satisfacción laboral y profesional de los profesores. Revista Lasallista de Investigación, 13(1), 214-226.

Cernas, D., Mercado, P., \& Davis, M. (2018). Perespectiva futura de tiempo, satisfacción laboral y compromiso organizacional: efecto mediador de la autoeficacia, la esperanza y la vitalidad. Journal of Work and Organizational Psychology., 34, 1-9.

Chiang, M., Núnez, A., Martín, M., \& Salazar, M. (2010). Compromiso del Trabajador hacia su Organización y la relación con el Clima Organizacional: Un Análisis de Género y Edad. Compromiso del Trabajador hacia su Organización y la relación con el Clima Organizacional: Un Análisis de Género y Edad, 28(40), 90-100.

Conde, J., \& Martín, A. (2016). Potencialidades y necesidades de mejora en la formación. Revista Electrónica de Investigación Educativa, 18(1), 140-152. Obtenido de http://redie.uabc.mx/redie/article/view/767 


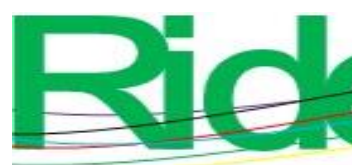

Revista Iberoamericana para la Investigación y el Desarrollo Educativo

ISSN $2007-7467$

Fernández, E. (2017). Una mirada a los desafíos de la educación superior en México. Innovación Educativa, 17(74), 183-207.

Ganga, F. A., Ramos, M. E., Leal, A. G., \& Valdivieso, P. E. (2015). Teoría de agencia (TA): supuestos teóricos aplicables a la gestión universitaria. Innovar, 25(57), 11-26. doi:doi: 10.15446/innovar.v25n57.50324

García, O., Pérez, R., \& Miranda, A. (2018). Los profesores investigadores universitarios y sus motivaciones para transferir conocimiento. Revista Electrónica de Investigación Educativa, 20(3), 43-55. doi:https://doi.org/10.24320/redie.2018.20.3.1754

Gogan, L. M., Artene, A., Sarca, I., \& Draghici, A. (2016). The Impact of Intellectual Capital on Organizational Performance. . Procedia - Social and Behavioral Sciences, 221, 194-202. doi:https://doi.org/10.1016/j.sbspro.2016.05.106

Gómez, M. (2011). Estimación de los modelos de ecuaciones estructurales, del índice mexicano de la satisfacción del usuario de programas sociales mexicanos, con la metodología de mínimos cuadrados parciales. Tesis. México: Universidad Iberoamericana. Obtenido de http://www.bib.uia.mx/tesis/pdf/015422/015422.pdf

González, F., López, T., \& Sánchez, S. M. (2014). Satisfacción laboral y compromiso organizativo en los recursos humanos de la hostelería de Córdoba. Intangible Capital, 10(1), 89-211. doi:http://dx.doi.org/10.3926/ic.489

Hair, J., Hult, G., Ringle, C., \& Sarstedt, M. (2014). A primer on partial least squares structural equation modeling (PLS_SEM). Estados Unidos de América: SAG Publications, Inc.

Hashim, M., Osman, I., \& Alhabshi, S. (2015). Effect of Intellectual Capital on Organizational Performance. Procedia-Social and Behavioral Science, 211, 207-214. doi:https://doi.org/10.1016/j.sbspro.2015.11.085

Hernández, C. A., \& Ramos, J. R. (2018). La Inteligencia emocional y la práctica docente en profesores investigadores. Revista Iberoamericana para la Investigación y el Desarrollo Educativo, 9(17), 1-29. doi:DOI: 10.23913/ride.v9i17.387

Hernández, R., Fernández, C., \& Baptista, P. (2014). Metodología de la Investigación. México: McGraw Hill. 


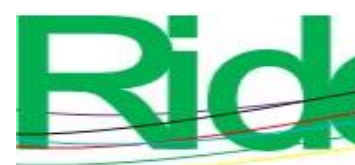

\section{Revista Iberoamericana para la Investigación y el Desarrollo Educativo \\ ISSN $2007-7467$}

Hernández, R., Méndez, S., \& Contreras, R. (2014). Construcción de un instrumento para medir el clima organizacional en función del modelo de los valores de competencia. Contaduría y Administración, $\quad$ 59(1), 229-257. Obtenido de https://dialnet.unirioja.es/servlet/articulo?codigo=5118462

Hinkin, T. (1995). A review of scale development practices in the study of organizations. Journal of Management, 21(5), 967-988. doi:doi: 10.1177/014920639502100509

Hussinki, H., Ritala, P., Vanhala, M., \& Kianto, A. (2017). Intellectual capital knowledge managament practices and firm performance. Journal of Intellectual Capital, 18(4), 904922. doi:https://doi.org/10.1108/JIC-11-2016-0116

Linda, M., \& Fitria, Y. (2019). The effect of intellectual capital on job satisfaction on bank amployees. Revista de Ciencias Humanas y Sociales, 35(19), 1244-1265. Obtenido de http://produccioncientificaluz.org/index.php/opcion/article/view/24080/24524

Locke, E. A. (1969). What is job satisfaction? Organizational Behaviour and Human. Performance, 4, 309-336. doi:http://dx.doi.org/10.1016/0030-5073(69)90013-0

Lupano, M. L., \& Castro, A. (2018). Influencia de virtudes organizacionales sobre satisfacción, compromiso y performance laboral en organizaciones argentinas. Interdisciplinaria, 35(1), 171-188.

Martínez, M., \& Fierro, E. (2018). Aplicción de la técnica PLS_SEM en la gestión del conocimiento: Un enfoque técnico práctico. RIDE Revista Iberoamericana para la Investigación y el Desarrollo Educativo, 8(16), 130-164. doi:DOI: 10.23913/ride.v8i16.336

Mondéjar, J. (29 y 30 de Noviembre de 2017). Modelos de Ecuaciones Estructurales con PLS (Partial Least Squares). Obtenido de V Jornadas de Investigación Científica del Turismo: https://riuma.uma.es/xmlui/bitstream/handle/10630/14917/AN\%C3\%81LISIS\%20CR\%C 3\%8DTICO\%20DE\%20LAS\%20FUENTES\%20ESTADISTICAS\%20DEL\%20TURISM O.pdf? sequence $=1$

Montanares, E. G., \& Junod, P. A. (2018). Creencias y prácticas de enseñanza de profesores universitarios. Revista Electrónica de Investigación Educativa, 20(1), 93-103. doi:https://doi.org/10.24320/redie.2018.20.1.1383

Nahid Naderi, A. (2012). Teachers: emotional intelligence, job satisfaction, and organizational commitment. Journal of Workplace Learning, 24(4), 256-269. doi:ttps://doi.org/10.1108/13665621211223379 


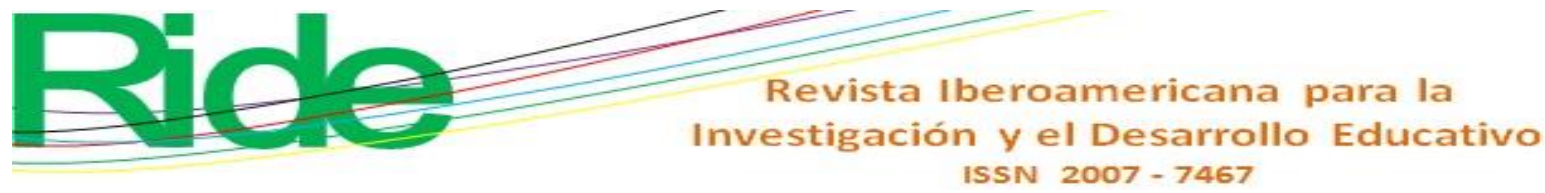

Nava, R., \& Mercado, P. (2011). Análisis de trayectoria del capital intelectual en una universidad pública Mexicana. Revista Electrónica de Investigación Educativa., 13(2), 166-187. Obtenido de http://www.scielo.org.mx/pdf/redie/v13n2/v13n2a12.pdf

OCDE. (2017). ESTUDIOS ECONÓMICOS DE LA OCDE: MÉXICO 2017. OCDE.

OCDE. (2019). Higher Education in Mexico: Labour Market Relevance and Outcomes, Higher Education. OECD Publishing, Paris, 1-44. doi:https://doi.org/10.1787/9789264309432

Pantoja-Aguilar, M. P. (2019). Indicadores de desempeño académico como predictores de captación de recursos financieros. Convergencia Revista de Ciencias Sociales, 79, 1-27. doi:https://orcid.org/0000-0002-8337-5427

Pedraza, N., Lavín, J., Marmolejo, J., Vasconcelo, R., \& García, J. (2017). Caracterización del capital intelectual en el sector empresarial del estado de Tamaulipas,México. Visión $\begin{array}{llll}\text { Gerencial, } & 1, & \text { 119-143. } & \text { Obtenido }\end{array}$ http://www.redalyc.org/jatsRepo/4655/465549683009/html/index.html

Pedraza, N. A. (2018). El clima organizacional y su relación con la satisfacción laboral desde la percepción del capital humano. Revista Lasallista de Investigación, 15(1), 90-101. doi:10.22507/rli.v15n1a9

Rodríguez, A., Retamal, M., José, L., \& Cornejo, F. (2011). Clima y satisfacción laboral como predictores del desempeño: en una organización estatal chilena. Salud \& Sociedad, 2(2), 219-234. doi: https://doi.org/10.22199/S07187475.2011.0002.00007

Rubio, A. (2016). Capital humano y sociedad de control. Cuadernos de Filosofía Latinoamericana, 37(115), 103-126. doi:doi:10.15332/s0120-8462.2016.0115.04

Ruíz, M., Pardo, A., \& San Martin, R. (2010). Modelos de ecuaciones estructurales. Papeles del psicólogo, 31(1), 34-45. Obtenido de https://www.redalyc.org/pdf/778/77812441004.pdf

Spector, P. E. (1985). Measurement of Human Service Staff Satisfaction:. American Journal of Community Psychology,, 13(6), 693-713. Obtenido de https://link.springer.com/content/pdf/10.1007\%2FBF00929796.pdf

Taliadorou, N., \& Pashiardis, P. (2015). Examining the role of emotional intelligence and political skill to educational leadership and their effects to teachers' job satisfaction. Journal of Educational Administration, 53(5), 642-666. doi:http://dx.doi.org/10.1108/JEA-02-20140025 


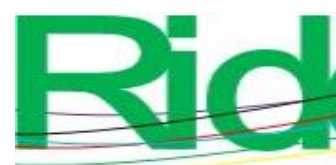

Revista Iberoamericana para la Investigación y el Desarrollo Educativo ISSN $2007-7467$

Zenteno Hidalgo, A., \& Durán, S. (2016). Factores y prácticas de alto desempeño que influyen en el clima labora: Análisis de un caso. INNOVAR, Revista de Ciencias Administrativas y Sociales, 26(59), 119-135. doi:doi: http://dx.doi.org/10.15446/innovar.v26n59.54367 